\title{
Cycling Traffic Development in Slovakia in the Terms of the City of Košice
}

\author{
Hana Neradilová ${ }^{1,}$, and Tomáš Ragulský ${ }^{2}$ \\ ${ }^{1}$ College of Logistics, Přerov, Palackého 1381/25, 75002 Přerov, Czech Republic \\ ${ }^{2}$ Technical University of Košice, BERG Faculty, Park Komenského 14, 04001 Košice, Slovakia
}

\begin{abstract}
Cycling traffic has been booming in urban agglomerations recently. This is due to the fact that using bicycles helps solve existing transport problems. The advantage is that it supports the limitation of the use of cars in city centers and thus reduces the negative impact of transport on the environment. It can be realized in various forms - using private bicycles or bike-sharing. Košice includes among cities where introducing bike-sharing is considered. Košice is a city that has its specific transport problems, whose partial solution may be to increase the support of cycling when one of the options is the introduction of a city bike-sharing system. The article offers a closer perspective at this issue in adaptation to real urban conditions. It introduces the possibility of introducing support for cycling traffic in the city of Košice based on the selection of suitable locations for building the stations and the subsequent evaluation of selected localities based on the determined criteria using the proportional index method.
\end{abstract}

\section{Introduction}

Cycling traffic and cycle tourism have an irreplaceable place in the field of transport today. Using cycling is constantly raising, thus increasing the requirements for integrating cycle routes, off-street cycle paths and the availability of historic city centers on a bicycle. Bicycle gradually regains its status as a significant part of the transport infrastructure and is no longer perceived only as a form of sporting activity. In many cities, it becomes a faster and more efficient mode of transport than a car. The full inclusion of bicycles in the city transport system is a necessary way to support the fluent flow of traffic. The current trend in cycle tourism is to increase the number of cycling routes and cycle paths. One of the options for pedestrians, cyclists, and drivers to co-operate is the introduction of public bicycle sharing system - bike-sharing, which works as a public automated bicycle rental. It is a network of mutually interconnected bicycle stands that serve the general public.

In the context of increased efforts to increase the involvement of cyclists in public transport, it is necessary to solve important aspects such as the safety of bicyclists in mixed urban traffic, which is addressed by Apasnore et al. [1] in relation to the impact of the lateral spacing between bicycles and vehicles and other factors. Other authors [2] examined

* Corresponding author: hana.neradilova@vslg.cz 
bicycle sharing issues in Polish conditions based on the attitude of the Poles towards cycle traffic and the idea of a self-service public bike rental system has been widely presented and the components of the architectural system have been discussed. The authors presented the principle of bike-sharing, as well as its transport accessibility in cities in Poland. Cairns et al. [3] presented interesting findings in the study of a change in people's behavior in relation to the use of electric bikes if people could use these vehicles for several weeks free of charge. In their study, they concluded that almost a third of the surveyed number of people in the future intends to use this mode of transport much more often, and nearly three-thirds would like to own the electric bicycle as an efficient mode of transport. Waard et al. [4] investigated the influence on the behavioral change of cyclists when the common map or smartphone navigation is used for orientation. Prateli et al. [5] have dealt with improving bicycle mobility in urban areas through ITS technologies. In connection with cycle traffic and its involvement in urban transport, Wang et al. [6] have investigated the effect of the distance of moving targets on the emergence of different types of conflicts between vehicles and bicycles at signaling crossroads. In solving the issue of launching public bicycle system the experiences from different world destinations such as Taipei [7], Fargo in North Dakota [8] and Beijing [9] are beneficial. When introducing a bike sharing system, it is also important to address the issue of proper station distribution, for example, using a mathematical model [10] or interpolation techniques [11].

There is often a distinction between mobile and static cycling infrastructure in literature. Measures to improve cycling are usually related to mobile infrastructures, such as cycling routes. This includes the construction of cycling paths (on-street, off-street) paths or multifunctional crossings. The stationary bicycle infrastructure includes all types of bicycle parking, ranging from simple bicycle racks to high-quality bicycle stations with a wide range of services. Therefore, if there is a purpose to support cycling in a city or community, more attention should be paid to improving conditions for stationary cycling infrastructure. Building bicycle parking facilities enormously improve the conditions for cyclists.

\section{Cycling usage in urban agglomerations}

As part of the development of cycling traffic in urban agglomerations, it is necessary to consider several factors - the possibility of parking the bicycles, the location, and choice of bicycle rack type, the purpose of building a certain station for bicycles, etc. Proper cycle racks are such racks that allow a bicycle to be locked on frame and wheel. Parking does not only include the right cycle racks but also the locations where the cycle stands are situated. In general, stands should be located at every type of civic amenities such as school, office, sports facility, theatre, cinema, shop, and others. Parking in terms of location may be in the associated traffic area on the pavement, but it can also be located in the main traffic area in the parking lane or in an unused location on the road, where, for example, it fulfils the role of the calming element [12]. Bicycle racks should be placed in front of any type of civic amenities available on a bicycle. Co-operation with the citizens themselves has proven very well in selecting new locations when citizens are asked about where do they the stations with bicycle racks need. This way was used for example in the city of Zilina, where the design of new sites for cyclists was based on suggestions from citizens.

The main principles for the appropriate placement of bicycle racks are to place them as close as possible to the entrance, place them in a visible place or where a large movement of persons is around, and place them within the reach of surveillance cameras. Another condition is a good access to cycling path or route, the possibility to protect the bicycle from damage and to enable the locking of the frame and the front or rear wheel with a short wheel lock. Cycle racks should not endanger passers, for example, to restrain pedestrians walking on pavement. 
From a safety point of view, cycle stands can be divided into three types. These are cycle racks that allow safe locking of the wheel and frame or locking into a lockable and guarded shelter or box. Cycle racks that allow only wheel or frame locking and those that do not allow locking the bicycle only parking into, for example, grooves. In this case, the bike needs to be guarded personally and supervised.

From a time perspective, short and long-term parking is distinguished. Short-term parking includes a parking time up to 3 hours, what may include dealing certain matters at the office, post office, shopping, etc. Long-term parking means a period longer than 3 hours and represents the type of parking when the cyclists put off the bicycle for a longer period of time, for example, time at work and school, during the night at the house.

\subsection{The current state of the bicycle traffic system in Slovakia}

Many Slovak cities and municipalities have not even a single kilometre of cycling paths. Even where they are built, unsatisfactory technical solutions often impedes their usability. This is related to the lack of a high-quality and detailed technical regulation that would be devoted to the design and building of cycling infrastructure and the minimum attention paid to cycling. The technical condition of road infrastructure in cities and towns in Slovakia is unfavourable. Absent of segregated communications network, cyclists are forced to use road communications where they are endangered by cars. This fact discourages many people from using cycling. Negative features include road inequality and frequent confining of cyclists by cars passing through cycling routes. These elements aggravate the comfort of cycling and also increase the risk of accidents and injuries.

In Slovakia, there is also the lack of cycling infrastructure documentation, which confirms the fact that the potential of cycling is still underestimated. For making out this documentation, 138 cities were addressed in the year 2012, of which only 67 cities have participated the survey. According to data from these 67 cities, the total length of cycling routes was nearly $150 \mathrm{~km}$. Up to three-fifths consists of separate communications - either exclusively for cyclists $(15 \%)$ or more often for pedestrians and cyclists with separate traffic $(23 \%)$ and with mixed traffic $(22 \%)$. A third of the total length is formed by off-road cycle paths built in the associated transport area, of which the movement of cyclists is separated on $16 \%$ and on more than $18 \%$ is movement of cyclists mixed with the movement of pedestrians. Only $6 \%$ of the cycling communications lengths in the cities participating in the survey are located in the main traffic area (cycling lane, cycling route, on-street sharrow), (Fig. 1).

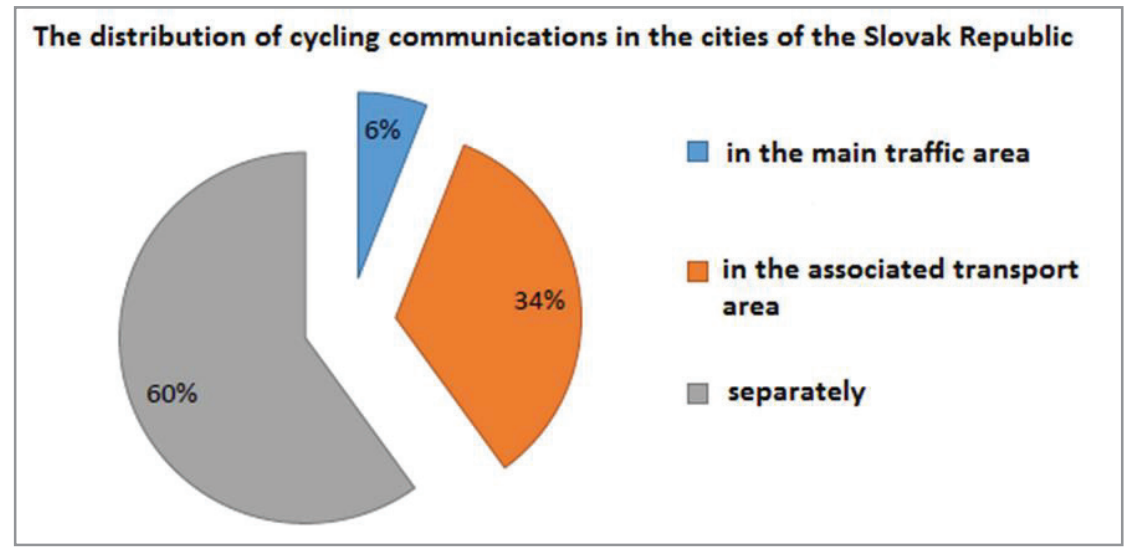

Fig. 1. The distribution of cycling communications in the cities of the Slovak Republic. Source: authors 
Cities often do not deal with cycling issues in obligatory parts of regional planning documents. Only 29 of the city of the 67 cities involved in the survey have mentioned cycle transport in their urban plan. Only four cities - Trnava, Moldava nad Bodvou, Piešt'any and Banská Bystrica - have developed a separate non-motorized transport conception document and 19 cities have a technical study of bicycle routes. Two cities, Moldava nad Bodvou and Banská Bystrica, have static cycling traffic studies. The role of the cycle-coordinator is currently set up by the city authorities in Banská Bystrica, Bratislava, and Trnava.

\subsection{Cycling infrastructure in Slovakia}

Cycling route is a marked trail for cyclists in the terrain along existing roads. Cycling route can be guided by intravilan, extravilan, in forest, mountain, or field. At the same time, after their legislation in the sense of Slovak legislation, cycling routes must be fitted with orientation cycling marking.

There are 530 marked cycling routes in Slovakia with a total length of more than 10,000 kilometres. The main axes consist of $2,926 \mathrm{~km}$ national long-distance cycling trails, international routes and Eurovelo routes, of which $82.6 \mathrm{~km}$ are now marked on the territory of the Slovak Republic. They are defined in regional planning documents and the cycling traffic conception document that respect broader relationships and major national corridors. Regional and local routes account for $70 \%$ of all cycling routes of nearly $7,000 \mathrm{~km}$. The network of cycling routes in Slovakia is run by 74 subjects, mostly civic associations. The leading part of the cycle routes network is managed by the associations covered by the Slovak Cycle Club. Partially the cycling routes administration was taken over by the municipalities - the city of Bratislava, the city of High Tatras, the town of Spišská Belá, the association of municipalities of the Tokay region, the village of Pila, and the town of Skalica (Tab. 1).

Table 1. Cycling routes by region. Source: authors

\begin{tabular}{|l|c|c|c|}
\hline \multicolumn{1}{|c|}{ Self-governing region } & $\begin{array}{c}\text { Number of } \\
\text { administrators }\end{array}$ & $\begin{array}{c}\text { Number of } \\
\text { routes }\end{array}$ & $\begin{array}{c}\text { Length } \\
{[\mathbf{k m}]}\end{array}$ \\
\hline Bratislava Region & 12 & 41 & 749 \\
\hline Trnava Region & 7 & 56 & 804 \\
\hline Nitra Region & 6 & 21 & 387 \\
\hline Trencin Region & 6 & 64 & 1,178 \\
\hline Zilina Region & 6 & 112 & 2,200 \\
\hline Banska Bystrica Region & 11 & 106 & 2,140 \\
\hline Presov Region & 13 & 76 & 1,350 \\
\hline Kosice Region & 13 & 54 & 1,291 \\
\hline Total & $\mathbf{7 4}$ & $\mathbf{5 3 0}$ & $\mathbf{1 0 , 0 9 9}$ \\
\hline
\end{tabular}

Cycling routes are divided as follows:

- by the nature of the terrain: road and mountain biking,

- according to the importance expressed in colour: red - blue - green - yellow,

- by intensity: recreation - sport - expert.

The marking for cycling tourism is regulated by the Slovak Technical Standard - STN 018028 - Cycling marking. The most of the cycling trails in Slovakia are marked with red colour $(2,926 \mathrm{~km})$, followed by cycling routes marked with blue colour $(2,896 \mathrm{~km})$, then green trails $(2,588 \mathrm{~km})$ and yellow marked cycling trails $(1,220 \mathrm{~km})$. Suitable trails for road bikes are about $47 \%$, for mountain bikes about $53 \%$ of the total length of marked cycling routes. 


\section{Analysis of cycling traffic in the city of Košice}

Cycling infrastructure in the city of Košice does not achieve the required quality. The number of cycling paths is deplorably low and the infrastructure for cycling around the city center is missing or insufficient. Košice has a limited range of cycling paths along the Hornad River (from the city part Nad jazerom to the city center), then on the north-south route on the pavements Južná - Hlavná - Komenského and the cycling paths on the sidewalks in the suburban part West. Dargovskych hrdinov housing estate does not have enough access for bicyclists. There are no bicycle lanes in the residential areas, and bicyclist there use mainly sidewalks.

Recreational paths are not well connected to urban communications. Crossings between paths and communications are often dangerous, light-controlled crosswalk usually causes pedestrians a long delay. The proportion of cycling routes is about $2 \%$, but it is growing rapidly. The current arrangement of sidewalks with enable movement of bicycles will face problems and conflicts between the both groups (pedestrians and bicyclists). This problem has been already in the Hlavná Street. The total length of urban cycling routes in the city is $22,767 \mathrm{~m}$ (Fig. 2) and their distribution is the following.

City cycling routes in the main traffic area:

- cycling on-road lane - $211 \mathrm{~m}$,

- cycling on-road route - $692 \mathrm{~m}$,

- cycling on-street sharrow - $0 \mathrm{~m}$,

- $\quad$ crossing for cyclists $-477 \mathrm{~m}$.

City cycling routes outside the main traffic area:

- separate cycle path - 6,070 m,

- the shared path for pedestrians and bikers with mixed traffic - $72 \mathrm{~m}$,

- $\quad$ the shared path for pedestrians and bikers with separate traffic $-15,245 \mathrm{~m}$.

The cycle traffic share in Košice in the total transport work division is only 3 percent (Survey - BICY, Cities and Regions for cycling). In accordance with the vision of the National Cycling and Cycling Tourism Development Strategy in the Slovak Republic, which foresees a 10 percent share of bicycle transport in the total transport work division by the year 2020, the current state of affairs is not adequate. In order to achieve the desired status, it is necessary to start building a safe traffic area for cyclists and setting up attractive cycling routes. Currently, a cycling network of $26 \mathrm{~km}$ in the city and $146.8 \mathrm{~km}$ of cycling routes in the Municipal Forests is being built in Košice. Košice has ranked second in the length of urban cycle routes after the first Bratislava. Taking into account the number of inhabitants supposed to use cycle routes or the length of cycling trails related to the size of the city, Košice has come 7th and 6th out of ten cities. In Košice, segregation of cycling infrastructure prevails. Most urban cycling routes (up to 96\%) are led outside the main transport area along with separate walkways or shared paths for pedestrians and cyclists. The remaining infrastructure consists of on-road cycle lanes and on-road cycle routes, which is less than $1 \mathrm{~km}$ in length.

\section{Proposal of bicycle stands location in Košice}

Proposal of the station locations within the bike-sharing system was based on experience from a similar system in New York [13], according to which the main criteria for station placement should be the capacity of stations, their relatively high density and also proximity to public transport. An important aspect is also the feedback from the community, which has not been taken into account in this proposal since it is only the initial design of station placement. Stations suggested for the bike-sharing system are close to the 
objects with the high-frequency of people such as schools, dormitories, department stores, shopping centers and various socially important buildings.

Altogether, 30 public bike-sharing stations were proposed (Fig. 3). Based on the proportional index analysis, the 15 most suitable stations were selected from this proposal.

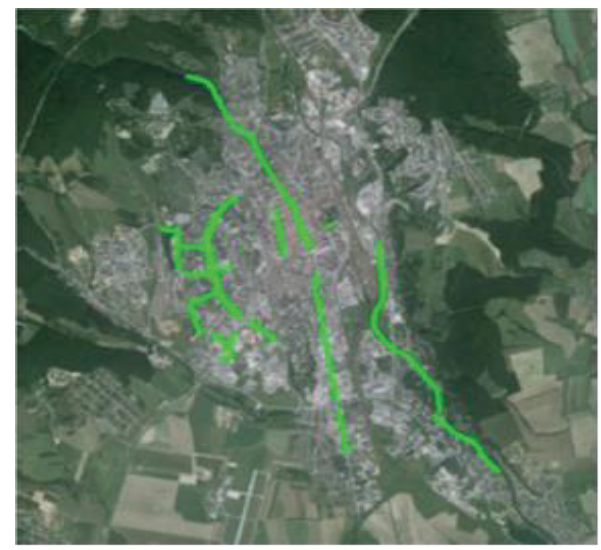

Fig. 2. Highlighting of city cycle routes in Košice

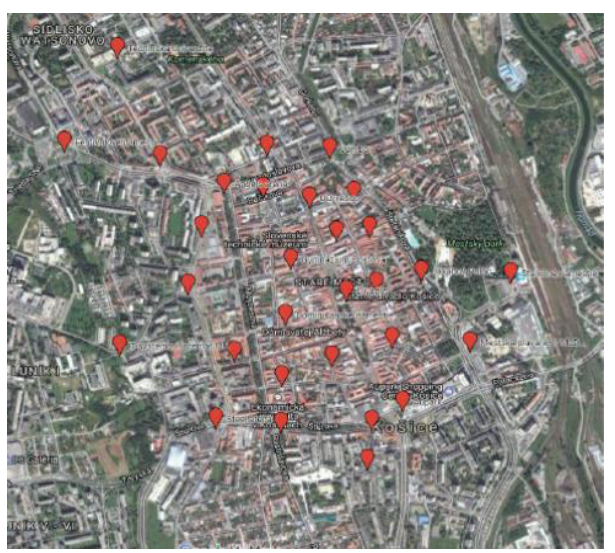

Fig. 3. Proposal of bike-sharing stations location

The four criteria with the following weights were defined to calculate the most suitable position of the stations (Table 2).

Table 2. The weighting of the criteria. Source: authors

\begin{tabular}{|l|c|}
\hline \multicolumn{1}{|c|}{ Criteria } & Weight of criterion \\
\hline Criterion 1 - proximity to public transport stops & 0.2 \\
\hline Criterion 2 - density of people & 0.3 \\
\hline Criterion 3 - purpose of the station & 0.4 \\
\hline Criterion 4 - proximity to cycling trails & 0.1 \\
\hline \multicolumn{1}{|c|}{ Total of weights } & 1.0 \\
\hline
\end{tabular}

Individual stations were assigned a number from 1 to 30 . Subsequently, individual stations were rated according to criteria on a scale of 1 to 10 (Table 3 and 4).

Table 3. Station rating - part 1. Source: authors

\begin{tabular}{|c|c|c|c|c|c|c|c|c|c|c|c|c|c|c|c|}
\hline Criteria/Stations & $\mathbf{1}$ & $\mathbf{2}$ & $\mathbf{3}$ & $\mathbf{4}$ & $\mathbf{5}$ & $\mathbf{6}$ & $\mathbf{7}$ & $\mathbf{8}$ & $\mathbf{9}$ & $\mathbf{1 0}$ & $\mathbf{1 1}$ & $\mathbf{1 2}$ & $\mathbf{1 3}$ & $\mathbf{1 4}$ & $\mathbf{1 5}$ \\
\hline Criterion 1 & 7 & 5 & 10 & 6 & 5 & 5 & 9 & 7 & 2 & 3 & 10 & 3 & 3 & 9 & 6 \\
\hline Criterion 2 & 7 & 4 & 7 & 5 & 10 & 3 & 7 & 4 & 7 & 7 & 7 & 7 & 8 & 9 & 7 \\
\hline Criterion 3 & 6 & 4 & 8 & 2 & 8 & 3 & 9 & 4 & 3 & 2 & 9 & 2 & 2 & 8 & 10 \\
\hline Criterion 4 & 8 & 3 & 8 & 8 & 5 & 8 & 10 & 6 & 4 & 4 & 4 & 3 & 3 & 5 & 4 \\
\hline
\end{tabular}

Table 4. Station rating - part 2. Source: authors

\begin{tabular}{|c|c|c|c|c|c|c|c|c|c|c|c|c|c|c|c|}
\hline Criteria/Stations & $\mathbf{1 6}$ & $\mathbf{1 7}$ & $\mathbf{1 8}$ & $\mathbf{1 9}$ & $\mathbf{2 0}$ & $\mathbf{2 1}$ & $\mathbf{2 2}$ & $\mathbf{2 3}$ & $\mathbf{2 4}$ & $\mathbf{2 5}$ & $\mathbf{2 6}$ & $\mathbf{2 7}$ & $\mathbf{2 8}$ & $\mathbf{2 9}$ & $\mathbf{3 0}$ \\
\hline Criterion 1 & 9 & 7 & 4 & 6 & 5 & 4 & 4 & 5 & 5 & 6 & 4 & 4 & 3 & 9 & 3 \\
\hline Criterion 2 & 10 & 6 & 5 & 9 & 10 & 4 & 3 & 4 & 9 & 8 & 4 & 1 & 10 & 6 & 5 \\
\hline Criterion 3 & 10 & 9 & 2 & 9 & 8 & 3 & 3 & 2 & 8 & 8 & 3 & 3 & 9 & 9 & 2 \\
\hline Criterion 4 & 2 & 2 & 9 & 8 & 7 & 7 & 5 & 3 & 6 & 5 & 5 & 3 & 8 & 3 & 6 \\
\hline
\end{tabular}


The individual station rating was then multiplied by the criterion weight. Using the ratio index analysis 15 stations with the highest rank in the total utility of the station $U_{m}$ were selected (Fig. 4). The evaluated stations were divided into two groups. The group with a total $\mathrm{U}_{\mathrm{m}}$ less than 5.8 was evaluated as unsatisfactory and the group with a total $\mathrm{U}_{\mathrm{m}}$ greater than 5.8 was evaluated as satisfactory.

Appropriate location of stations (Fig. 5): Steel Arena, Festival Square, Technical University, Angels Arena, Továrenská, Aupark Košice, Ondavská, Staničné Square, City Swimming Pool, Dominican Square, Pavol Jozef Šafárik University, Poštová, Tesco Store, Košice State Theater, Jakab Palace.

Inappropriate location of stations: Štúrova - Fejova, Štúrova - Rastislavova, Timonova, Vojenská, Zvonárska, Bočná, Hrnčiarska, Kováčska, Strojárenská, Kuzmány, Bačíkova, Kasárny námestie, Zimná, Mlynárska, Františkánska.

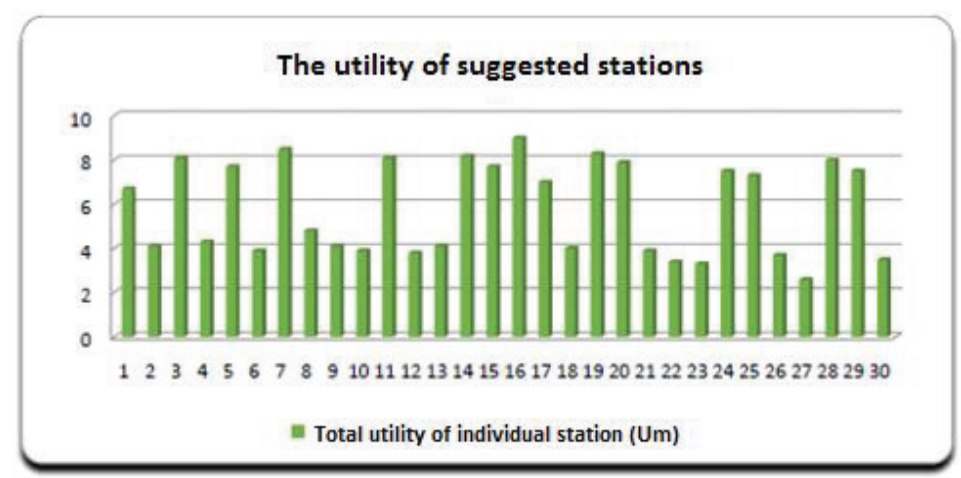

Fig. 4. The usefulness of individual stations. Source: authors

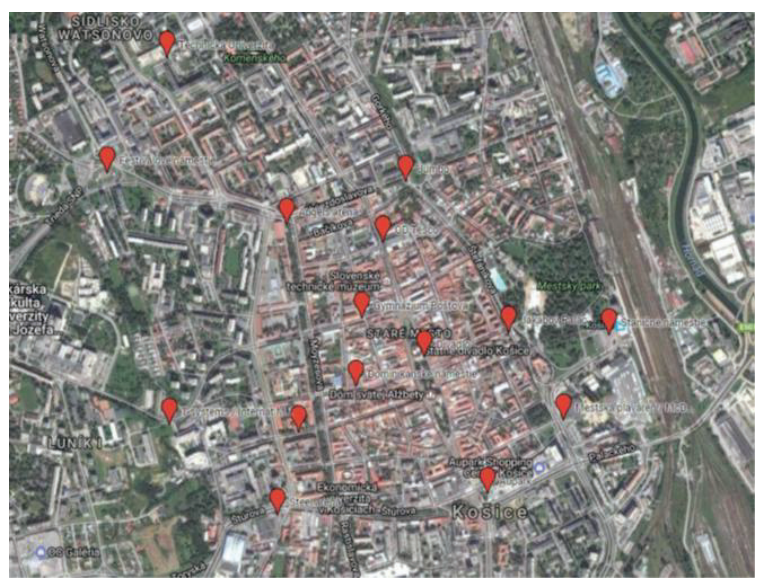

Fig. 5. Proposal of top 15 rated public bike-sharing stations. Source: authors

\section{Conclusion}

The idea to involve the form of recreational and leisure activities in public transport infrastructure is currently a topical theme in all major cities [14]. In the Slovak Republic, there is currently no official large-scale public bicycle system. There are only a few lowcost projects that run on volunteering and membership fees. 
In the paper, the proposal for the publicly bike-sharing system creation in the city of Košice was demonstrated on the selection of appropriate locations for the placement of cycling stands and racks for citizens. When selecting suitable locations, criteria such as proximity to public transport, connection to cycling paths for comfortable and safe engagement of cyclists into urban transport were taken into account. Furthermore, the purpose of the cycle station was solved, whether it is designed for short-term or long-term parking and the number of people who are supposed to use the station. These aspects are further developing the capacity design of the stations and its technical solution and then the proposal for charging this service for the inhabitants of the city of Košice. This proposal is a contribution to addressing congestion in the city center by car transport, including the lack of capacity for car parking. With the development of cycle traffic in the context of the popularity of the using this service by the citizens of the city, an improvement in the traffic situation in Kosice city can be expected.

This work is a part of the project VEGA 1/0063/16.

This paper is supported by the research project "From horse-drawn railway to intermodal transport" within Visegrad Fund.

\section{References}

1. P. Apasnore, K. Ismail, A. Kassim, Accident Analysis and Prevention 106, 141-148 (2017)

2. P. Czech, K. Turon, R. Urbańczyk, TSTP 2017 - 14th Scientific and Technical Conference on Transport Systems Theory and Practice 631 (2018)

3. S. Cairns, F. Behrendt, D. Raffo, C. Beaumont, C. Kiefer, Transportation Research Part A: Policy and Practice 103, 327-342 (2017)

4. D. de Waard, F. Westerhuis, D. Joling, S. Weiland, R. Stadtbäumer, L. Kaltofen, Ergonomics 60, 1283-1296 (2017)

5. A. Pratelli, M. Petri, A. Farina, and M. Lupi, TSTP 2017 - 14th Scientific and Technical Conference on Transport Systems Theory and Practice 631 (2018)

6. Y.Q. Wang, F. Xing, L. Zhang, 7th International Conference on Green Intelligent Transportation System and Safety 2016419 (2018)

7. J.J. Lin, N.L. Wang, C.M. Feng, International Journal of Sustainable Transportation 11, 633-641 (2017)

8. J. Mattson, R. Godavarthy, Sustainable Cities and Society 34, 174-182 (2017)

9. G. Sun, J. Zacharias, Sustainable Cities and Society 35, 323-330 (2017)

10. S. Zhang, Y. Ji, D. Sheng, J. Zhou, 7th International Conference on Green Intelligent Transportation System and Safety 2016419 (2018)

11. A. Ruda, L. Floková, I. Ivan, J. Horák, Inspektor T. (eds) Dynamics in GIscience, GIS OSTRAVA 2017, Lecture Notes in Geoinformation and Cartography, 383-388 (2018)

12. G. Fedorko, V. Molnár, J. Strohmandl, M. Vasil', Transport Means - 19th International Conference on Transport Means, 466-469 (Kaunas, Lithuania, 2015)

13. E. Jaffe, The Methodology of Bike-Share Station Placement in New York City, Available online: https://www.citylab.com/transportation/2011/10/how-new-yorkcity-will-choose-its-bike-share-stations/248/ (2011)

14. A. Kuptcova, P. Průša, G. Fedorko, V. Molnár, Transport Problems 11, 21-31 (2016) 